\title{
Redes de Governança e de Capital Social
}

\author{
João Seixas *
}

\begin{abstract}
$\mathrm{R}$
R esumo: Nacidade, as reconfigurações - empíricas e teóricas - em torno de conceptualizações e figurações de governação e de influência política e social (tais como as comunidades políticas, os actores socioterritoriais, ou mesmo os próprios processos e dinâmicas relacionais de influência e de tomada de decisão) têm constantemente acentuado os debates, os discursos e mesmo as operacionalidades em torno dos conceitos de governança urbana e de capital social. Será obviamente de carácter axiomático a interligação entre ambos, e entre os respectivos elementos de valoração. Especialmente quando a natural e desejada complexidade urbana, os coloca - e à sua hipotética consolidação - perante uma vasta e cruzada série de incertezas, de riscos, e também de expectativas.
\end{abstract}

Palavras-chave: Governança urbana; Capital social; Capital sociocultural.

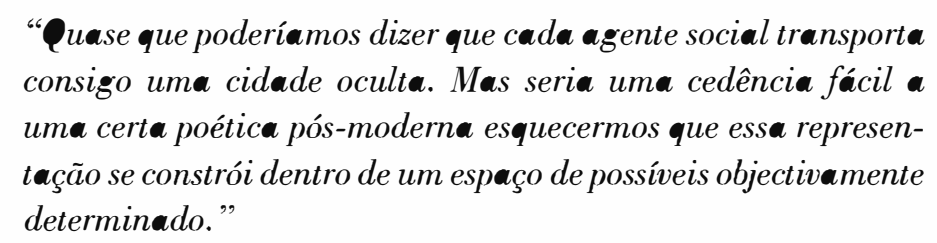

João Teixeira Lopes

Muitas das linhas de reconfiguração operadas, nos anos mais recentes, nos quadros de acção política e pública em torno da cidade europeia muito especialmente as baseadas nas perspectivas schumpeterianas que visam sobretudo o fomento do empreendedorismo urbano - e em simultâneo com a crescente valorização da acção política nas escalas da cidade, têm provocado um desenvolvimento de estruturas de liderança, de representação de interesses, e de tomada de decisões, mais próximas e mais interdependentes de determinados grupos de estatuto corporativo e económico. Esta evolução dos sistemas de acção política das cidades, enquadrada no âmbito das importantes alterações tanto de postura política de muitos eleitos, como das estruturas de mais-valias decorrentes da globalização económica, tem como base essencial da sua consolidação a própria reconfiguração das comunidades políticas, dos seus actores mais influentes, e dos próprios processos relacionais de tomada de decisão - reconfiguração particularmente evidente nos casos mais assumidos de regimes urbanos de competitividade. Esta ordem de evolução, que parece levantar, numa série de sectores sociais, crescentes questionamentos em torno da sustentabilidade de diversos modelos de qualificação urbana, face às diferentes paisagens sociopolíticas de cada cidade, parece suceder-se em maior ou menor grau, consoante uma série de determinadas - e, compreensivelmente, basilares - características de carácter mais endógeno existentes em cada território/sociedade urbana. Entre estas características, poderão destacar-se as ligadas à capacidade e propensão dos governos locais respectivos para

* Centr• de Estudøs Territøriais (ISCTE), Lisboa e Universidad Autónoma de Barcelona. Cøntacto: jseixas@claranet.pt 
actuar na contenção da crise pública e da fragmentação institucional, através de processos de modernização e de reforma administrativa e mesmo cultural (dotando os aparelhos públicos de uma melhor capacidade de governação perante os novos tipos de desafios), bem como as mais chegadas ao desenvolvimento de uma capacidade de mobilização e de envolvimento cívico da população urbana, questionando com maior acuidade as transformações em curso na política - e na qualidade das suas cidades. Este efeito, por sua vez, tem acrescentado novas variáveis e novas possibilidades nos cada vez mais recorrentes debates em torno das possibilidades de evolução da própria democracia.

Sobre o carácter relativamente excludente, e accionado por comunidades essencialmente fechadas, de diversos panoramas de governação de cidades, Short (1989) escreveu que, efectivamente, as estruturas da cidade real têm sido bem mais o resultado das culturas, da dialéctica e das decisões formadas entre os seus planeadores, os seus políticos e técnicos e os seus investidores privados, do que propriamente dos seus habitantes (vistos estes, e as suas acções, de uma perspectiva generalista). Esta tese, se por um lado realça a importância de se estabelecerem plataformas políticas e regulacionistas de carácter potencialmente desenvolvimentista entre actores primordiais, não deixa de colocar, igualmente, o cidadão - e suas formas de expressão - como ente também principal na construção e na reconstrução da cidade. Muito notavelmente, face aos novos panoramas informacionais e culturais, que abrem novas perspectivas de conhecimento, de exigência e de intervenção. Embora se reconheça um carácter de relativa exclusividade na formação do pensamento e da acção política, e ainda técnica (exclusividade, de resto, postulada desde os primeiros fundadores das bases da democracia representativa) essa relativa exclusividade deve, hoje em dia, basear-se não só em valores de ética e de responsabilidade pública, mas também, de forma ainda mais ampla, em novos valores de abertura, discussão e ainda de estruturas de responsabilização e de avaliação mais partilháveis. Valores que representam pilares de uma possível construção de índole mais colectiva - cultural, em primeiro lugar - quer face ao desenvolvimento das dimensões de estratégia e de planeamento, quer face ao próprio apro- fundamento dos valores da própria cidade e da cidadania. Num significativo desafio, de conciliar um carácter relativamente circunscrito na representação da condução política - inclusive para os campos da inovação e da reforma - com uma difusão tendencialmente mais alargada e mais participativa do sentido político na cidade.

Como temos visto, a evolução das políticas urbanas das cidades europeias tem levantado reflexões de carácter consideravelmente crítico, no âmbito de questionamentos em domínios centrais como o potencial aumento dos défices de democracia local, ou a efectiva qualificação da política nas cidades em ambientes discricionários. Em simultâneo, têm também surgido diversas propostas e mesmo experiências concretas de formas e práticas de inovação política (e democrática) que permitam reforçar os processos e os conteúdos democráticos na governação das cidades. Especialmente perante muitos indivíduos e muitas sociedades urbanas que, apesar das reconfigurações significativas nos campos mais privados e mesmo íntimos dos trajectos e relacionamentos individuais, mostram continuar a deter uma considerável consciência social, quer face à evolução da cidade em si mesma, quer perante a sua própria condição de seres políticos com direito (e dever) de expressão. É nestes (novos) âmbitos que se têm dirigido atenções para perspectivas de acção política ligadas a novos processos e estruturas que envolvam formas de interacção social e de expressão cívica, no fomento de uma cultura de cidadania, e na construção de novas formas de inclusão de tais expressões nos aparelhos político-administrativos de reflexão e de decisão (também eles em necessária reformulação), num reflexo sistémico e mais coordenado do que é a própria cidade, com seus actores e suas dinâmicas. Como aliás refere Nel.lo, a propósito da natureza da cidade: "um artefacto social particularmente complexo, no qual toda a intervenção favorece ou prejudica interesses de grupos ou de indivíduos" (2001, p. 5).

Esta relevância na afirmação de uma cultura de maior inter-relacionamento colectivo e do estabelecimento de redes de mais aprofundado comprometimento perante os desafios existentes, tem sido muito situada, conceptualmente, no âmbito de duas grandes dimensões: a governança urbana e o capital social (Maloney, Smith e Stoker, 2000). 
Muito particularmente, porque estes conceitos (e sua materialização efectiva) são entendidos, para muitos, como linhas de equilíbrio centrais, perante tendências excessivamente discricionárias no exercício do poder na cidade. É em torno destas duas perspectivas que debruçamos a nossa próxima atenção.

O debate em torno da governança urbana tem tido um crescente relevo em múltiplos areópagos. Por um lado, pelo seu enfoque nas formas de conjugação entre os actores sociais, entre diferentes culturas e dinâmicas, no sentido da construção e responsabilização para objectivos comuns. Por outro lado, pela atenção à existência de formas de condução e de gestão de tais fluxos e dinâmicas de conjugação - ou seja, gestão de formas de condução política mais plurais. Mas, por outro lado ainda, e justamente pelos enfoques referidos, pela sua capacidade de poder justificar a atenção e construção de uma estrutura de coligações efectivamente desenvolvidas sob um determinado espaço de governação (Jouve, 2003). Este potencial tem feito com que o conceito de governança urbana tenha sido, em significativa medida, apropriado não só por teóricos da acção colectiva, mas também por diversos círculos políticos e administrativos, tendo mesmo já entrado em muita da semiótica discursiva, justificando a existência ou a alteração de determinadas estruturas. Uma situação que em simultâneo tem trazido, sem surpresas, um aumento da dubiedade na materialização do conceito, perante a abertura de perspectivas e de justificações substancialmente distintas umas das outras.

Os debates em torno do conceito de capital social, apesar de mais antigos, mantêm-se com um potencial muito significativo. Mostrando deter características de cariz cultural e mesmo formativo, na consolidação das dinâmicas e das riquezas de uma sociedade, aos mais variados níveis, o conceito incorpora uma inquestionável correlação directa com a afirmação de valores essenciais à democracia. Atributos que podem não corresponder, em ordem similar, a lógicas evolutivas de governança urbana - que contém em si possibilidades de configurações cuja ordem pode ser perfeitamente discricionária. A capacidade de percepção e de apropriação de valores cívicos por uma comunidade - estando estes ligados a valores como a confiança, as expectativas, o sentido de direitos e de deveres, e ainda a estruturas como as redes de inclusão e de exclusão territorial - sendo sem dúvida condição relativamente difícil de medir ou de avaliar, não deixa de ser, certamente, dos mais essenciais pilares para a estruturação de um panorama de boa governação de uma cidade. Em simultâneo, e embora situando-se esta em esferas cujo âmbito poderá ser essencialmente cognitivo, não deixa de permitir posicionar uma série de vias consideravelmente claras, de acção política concreta, ao seu fomento. $\mathrm{O}$ que pode provocar - como provocou em diferentes cidades - impactos profundos nos universos da política e da governação urbana, colocando-se evidentemente como um dos pilares mais centrais no próprio desenvolvimento da cidade.

\section{A governança urbana - potencialidades e lacunas}

Conceito já relativamente antigo, a governança começou a ganhar corpo conceptual há cerca de três décadas, nas áreas económicas (particularmente nas escolas da economia institucional e de regulação). Apelando a uma abertura dos processos de reflexão e de decisão, nomeadamente por parte do Estado, na direcção de outros agentes sociais e económicos, o conceito coloca-se perante propostas de governabilidade de âmbito mais inclusivo e co-responsabilizante, em contraponto com linhas de governação entendidas como mais fechadas e/ou impositivas. Tornou-se, em importante medida, um conceito relativamente heurístico, mas em simultâneo aberto, proporcionando como tal um elevado potencial de dinâmica cumulativa nas estruturas de pensamento e de acção política mais recentes (Jouve, 2003). Condição bizarra mas particularmente relevante, quando em contextos de pensamento onde grande parte das análises (incluindo as mais críticas) se têm direccionado, precisamente, para as formas de condução de organizações humanas (Benko e Lipietz, 1994) levantando uma necessidade, ou mesmo urgência, no fomento de acções de índole mais colectiva. A reterritorialização do papel e das configurações do Estado, o aumento da participação dos actores sociais na composição e na responsabilização políticas e as crescentes preocupações face a práticas discricionárias e fragmentadas, foram colocando o conceito de governança, paulatinamente, no centro de diversas atenções. $\mathrm{E}$, face ao reposicionamento 
do papel das cidades no âmago da política e da economia global, uma das vertentes mais discutidas nestes âmbitos tem sido, precisamente, a da governança das cidades, ou a governança urbana.

Uma outra razão (de todo menosprezável) do sucesso do conceito, liga-se ao facto de este ter sido perfilhado por parte significativa tanto das escolas de pensamento anglo-saxónicas como das francófonas. A sua inclusão nas áreas das ciências sociais foi aprofundada pelos trabalhos de pensadores como Lindblom (1977), que contextualizou as interligações entre política e mercados, numa interdependência mútua, bem como pelos trabalhos de vários autores franceses em torno das novas relações entre diferentes níveis do aparelho de Estado (Le Galès, 1995). Ambas as correntes, ligadas por sua vez às reflexões em torno dos sistemas sociais e seus actores (nomeadamente por Crozier e Friedberg, 1977) e à estruturação conceptual de sistemas de acção colectiva (Guerra, 2002 e 2006a), constituíram estruturas de base para as asserções neo-pluralistas, de contextualização dos inter-relacionamentos entre os actores na acção política.

Dunleavy (1980) tinha já aprofundado alguns destes pontos de forma sistémica, escrevendo sobre as diferentes fontes de influência num dado contexto de decisão, fontes de influência largamente dispersas mas em semiformação de interesses, moldando assim as arenas da política - e da própria cidade. Com uma miríade de forças e de influências, não havendo um recorte predefinido de uma estrutura institucional preparada para a gestão de todas as diferentes interligações necessárias, bem como para os processos de discussão e de negociação, a actividade governativa torna-se assim progressivamente orientada por actividades processuais e negociais - a maioria delas de base informal incluindo demonstrações de poder e entendimentos tácitos entre forças desiguais. $\mathrm{O}$ conceito de governança urbana desenvolvido por este autor (id.) reconhece não só que uma parte da sua afirmação é devida às tendências para a fragmentação do poder, mas coloca a sua ênfase, sobretudo, na necessidade de conhecimento e de gestão das capacidades estratégicas dos diferentes actores, da diversidade dos processos de coordenação e da legitimidade das dinâmicas de negociação. Neste contexto, uma das grandes tónicas da governança urbana coloca-se, claramente, nas dimensões de processo e, muito especialmente, nas suas formas de estruturação e de gestão das dinâmicas e das relações entre os actores e suas perspectivas (Le Galès, 1995). Ou seja, na estruturação de espaços, vínculos e mecanismos para a geração de dinâmicas de reflexão mais conjunta, de confronto de ideias e da construção de consensos e de coligações, de formas de contratualização e de co-responsabilização, de processos de avaliação. As diferenças entre pessoas, organizações, redes de trocas, padrões de ocupação e de utilização do espaço, economias, culturas e instituições, parecem fazer com que a gestão e mediação da diversidade se tornem num dos principais desafios da governança urbana (Cohen, 2000) ${ }^{1}$.

Mas tal gestão da diversidade e da construção de dialéctica, de cooperação e de parcerias, embora sem dúvida ambiciosa, não será por si mesma suficiente. A alteração de governo para governança implica ainda, por parte das autoridades territoriais, a necessidade de estas não se deixarem arrastar para um mero quotidiano de gestão de processos de ordem esparsada e reactiva, num pano de fundo que se pode facilmente tornar fragmentado e muito dificilmente orientado. Implica, como tal, uma absoluta necessidade de se desenvolverem linhas e estruturas políticas de cariz relacional e em simul-

\footnotetext{
${ }^{1}$ A título de exemplo, a propósito da elaboração de propostas de políticas de revitalização urbana para as cidades portuguesas, foram listados alguns dos principais aspectos a ter em atenção na estruturação de sistemas de acção entre diferentes actores, perante um determinado território espacio-político de actuação (veja-se CET, 2005):

\& Nem todos os actores actuam ao mesmo nível, nem estão organizados por formas similares. Importa conhecer tais diferenças, de forma a se poderem estabilizar os "sistemas de regras e de funcionamento conjunto e as expectativas de desempenho mútuo" (id., p. 30);

2 Os actores partilham e/ou concorrem nas suas estratégias e nos seus objectivos. Importa conhecer e reconhecer mutuamente "os seus interesses, motivações, capitais de poder(es), capacidade e potencialidades de participação" (id., ibid.);

- "A incerteza, a turbulência e os conflitos são factores inerentes aos sistemas de acção que não podem e/ou devem ser evitados, mas cujos efeitos negativos ou desestruturantes podem ser minimizados" (id., ibid.);

\& Pode ser frequente a resistência à mudança "quando um sistema de acção se encontra em desenvolvimento e/ou inicia abordagens novas", tornando-se também necessário acautelar tais efeitos;

2 "O envolvimento dos actores e a promoção e viabilização de instrumentos de participação é um dos factores que contribui grandemente para o alargamento de possibilidades de desenvolvimento dos sistemas de acção e da sua produção em termos genéricos e generativos" (id., p. 31).
} 
tâneo pluralistas, sem dúvida, mas ao mesmo tempo com bases orientadoras e estratégicas, para o efectivo desenvolvimento da cidade como projecto político.

Estas perspectivas implicam, em paralelo com uma vigorosa condução política, uma racionalidade e sistémica de acção em torno de uma série de vectores. Vectores de alcance diverso, envolvendo diferentes atenções, actores e recursos, detendo cada um deles um valor próprio no aprofundamento de uma boa governação na cidade:

\section{a) A construção conjunta de estratégias} colectivas - Implementando, numa perspectiva estrutural, processos e espaços de discussão, concertação, contratualização e avaliação, entre os diferentes actores da cidade, envolvendo-os em co-responsabilização por um projecto colectivo;

b) $O$ fomento dos processos de descentralização e de reformulação territorial e sectorial de competências - Reconfigurando os necessários elementos territoriais, de responsabilidade e de condução pública, perante as novas exigências e perspectivas estratégicas urbanas - a diferentes níveis, do metropolitano/regional, ao da comunidade/ /bairro;

c) A promoção da cooperação vertical (público-público) - Aprofundando acções baseadas nos princípios da subsidiariedade e da reciprocidade, entre os diferentes níveis da administração, interligando actuações e responsabilidades, potenciando dinâmicas sincrónicas para atingir os objectivos;

d) A promoção da cooperação horizontal (público-público) - Ampliando as políticas e acções de co-responsabilidade entre diferentes agências públicas em áreas sectoriais diversas, especialmente aos níveis mais locais;

e) $\mathbf{O}$ aprofundamento da cooperação internacional - $\mathrm{Na}$ expansão de iniciativas de inter-relação e de acção conjunta entre agentes públicos e privados de territórios e de cidades diferentes;

f) O fomento das parcerias público-privadas - Desenvolvendo-se políticas, projectos e acções de trabalho conjunto, de acordo com uma estrutura de base estratégica, via processos de carácter institucional e de contratualização mas também via uma co-responsabilização de base cultural;

g) O fomento do envolvimento cívico Desenvolvendo-se instrumentos para uma maior participação dos agentes da sociedade civil nos processos de reflexão e de decisão política na cidade - às suas diferentes escalas - procurando-se por sua vez uma maior coresponsabilização destes e um aumento dos seus graus de motivação cultural para a participação;

h) A existência de processos de avaliação - Criando-se, nas próprias estruturas e processos de governança, linhas de questionamento e de análise crítica de natureza independente (e de preferência científica), no sentido da efectiva responsabilização e valorização das acções;

i) A disseminação de informação - Assumindo o pressuposto de que a existência e ampla divulgação de informação e de conhecimento - incluindo, evidentemente, o conhecimento científico - é um dos mais importantes vectores de transparência democrática, de inclusão sociopolítica e, no fundo, de co-responsabilização.

Numa outra óptica, Gomes (2003) propõe quatro categorias concretas de racionalidade, a ser seguidas, precisamente, numa paisagem política de boa governança (p. 399):

a) Racionalidade substantiva - Produto do conhecimento, consolida uma visão estratégica partilhada;

b) Racionalidade estrutural - Referente às estruturas dos processos de decisão e da articulação de competências;

c) Racionalidade procedimental - Define os procedimentos no jogo entre os actores;

d) Racionalidade avaliativa - Define os procedimentos e critérios de avaliação de resultados.

É neste sentido sistémico que algumas das ideias mais interessantes em torno da governança se têm expandido. Para Bagnasco e Le Galès, 
"governança define-se como um processo de coordenação de actores, de grupos sociais e de instituições, no sentido de atingir objectivos colectivamente discutidos e definidos, em ambiente fragmentado ou mesmo nebuloso" (2000, p. 26). Implica, como tal, uma estrutura de regulação, de instrumentos e de mecanismos para que tal coordenação se dê com uma considerável dose de objectividade, e no prosseguimento de determinados - e, certamente, discutidos - fins. E tais ênfases implicam, naturalmente, a predisposição de (pelo menos) um elemento central que gira ou conduza a estruturação de tais espaços, instrumentos e vínculos, bem como uma atenta gestão de stakeholders e dos valores de inclusão política (Jessop, 1994): tal tarefa de design da geografia política na cidade deve caber em importante medida ao governo urbano, porque eleito. Mas é uma tarefa que contém, em si mesma, um amplo potencial centrífugo, transportando potencialidades de uma melhor governabilidade tanto em termos do envolvimento dos diferentes actores públicos (que podem deter novas responsabilidades) como dos demais actores sociais da cidade. Para Gomes, atento analista das necessidades de reforma na administração pública, "o primado da governança não reflecte, necessariamente, menor governabilidade, traduz sim, desta, um conceito diferente do anteriormente expresso. Trata-se, sobretudo, de desenvolver um modo de governação que permita ao mercado operar e viabilize a participação activa dos cidadãos nas tomadas de decisão. Se o Estado tem uma menor capacidade de ditar, formalmente, a concepção das políticas, pode controlar de forma mais efectiva a sua implementação, na medida em que cooptou para a condução do processo interesses sociais que, a não ser assim, poderiam obstaculizar o desenvolvimento das políticas em causa. A governança supõe, em última análise, um governo mais atento aos limites da sua esfera de acção e que saiba trabalhar com eficácia no âmbito dos padrões estabelecidos" (2003, p. 390).

Colocado desta forma, o conceito de governança urbana mostra não só a sua complexidade, como também as suas amplas potencialidades no fomento da cooperação e da política na cidade. $\mathrm{Na}$ verdade, no melhor dos seus sentidos, centrada nos âmbitos da cidade como actor colectivo, a governança tem objectivos mais ambiciosos do que a própria operacionalização da diversidade e do conflito numa miríade de iniciativas e de políticas. Bagnasco e Le Galès, dois dos mais conhecidos analistas contemporâneos nesta área, realçam que um dos maiores objectivos da governança é “ir para além das problemáticas da eficiência e da coordenação, no sentido de reincorporar uma dimensão social e política" (2000, p. 26). Procurando-se, por conseguinte, ir não só na direcção do desenvolvimento concreto de coligações e de parcerias - com fins específicos, mesmo as de escala mais amplamas ainda, de forma bem mais abrangente, na construção de quadros cognitivos culturais de maior conhecimento, de maior inclusão e responsabilidade cívica e de maior motivação, em torno de objectivos partilhados e comuns, sendo como tal projectos mais colectivos. Vertentes, enfim, que vão no sentido de um aprofundamento do capital social da cidade ${ }^{2}$.

Ou ainda, como Fernandes escreveu (2004), "é indispensável uma clara melhoria da tradicional representação política, para que os cidadãos reganhem a confiança nas instituições". E, nesse contexto, "à imaginação política se impõem, actualmente, a tarefa e o desafio de descobrir os mecanismos capazes de integrar, no mesmo sistema político, as modalidades formais e não formais da democracia (...) para realizar esse complexo objectivo, as sociedades parecem carecer de um forte investimento em cultura cívica e em cultura política (...) O poder político, porque actor importante na construção de mais democracia, não pode ser o redutor da participação, mas antes o seu multiplicador", havendo assim que "desfeitiçar e desnaturalizar as formas tradicionais de exercício da política". (pp. 50-57).

Sendo muito ambiciosas, as premissas da governança urbana contêm, no entanto, importantes dubiedades a que há que dar atenção. O fomento de uma boa governança, trabalho que se afigura evidentemente aliciante mas muito complexo,

\footnotetext{
2 Para uma análise mais detalhada sobre os processos de desenvolvimento sistémico do conceito, e da introdução nos discursos e práticas políticas da governança urbana, veja-se ainda: Hirst (1993), Esser e Hirsch (1994), Mayer (1994), Lipietz (1994), Judge (1995), Gaudin e Novarina (1997), Amin e Hausner (1997), Bennett (1997), Jouve e Lefèvre (1999a), Le Galès (2000) ou Lorrain (2000a).
} 
requer um elevado esforço de condução política muito particularmente perante a capacitação de processos de inovação e de reforma do statu quo, e face a panoramas em importante medida constituídos por culturas político-administrativas socialmente instituídas, e de sistemas relacionais e de interesses muito consolidados. Porém, as transformações em curso nos quadros da acção pública nas cidades, embora muito significativas, não têm necessariamente conduzido a uma qualificação da maioria dos sistemas políticos urbanos - em importante medida, devido precisamente à falta de capacidade (ou de vontade) de uma ampla condução política por parte dos líderes e das elites urbanas. Que, em muitas cidades, e apesar de alterações nos padrões de governança, têm direccionado os ambientes de acção política para estruturas de acção e, algumas vezes, para regimes urbanos concretos orientados para fins específicos de empreendedorismo, de domínio relativamente corporativista e discricionário (Pierre, 1999).

O desafio da governança urbana, embora pleno de potencial, corre também ele o risco de implementação parcial e fragmentada, em projectos espaçados e perante comunidades de interesses parcelares - não atingindo assim, de todo, os seus propósitos mais ambiciosos de aprofundamento social e político. Bagnasco e LeGalès (2000) finalizam o seu livro destacando este ponto: “’̀ medida que a governança urbana se vai tornando mais institucionalmente fragmentada, grupos de interesses externos podem beneficiar de mais pontos de entrada do que nunca, desenvolvendo-se um muito mais complexo sistema de inter-relacionamentos e de interdependências entre agências estatutárias e grupos não-estatutários. Que a complexidade e a contingência se tenham tornado a ordem do dia só pode surpreender quem ainda acredita que a simplicidade e a previsibilidade são, ou deveriam ser, o estado natural da governança urbana" (p.197).

Neste âmbito, recordaríamos Touraine, quando disserta sobre as possibilidades de integração natural dos diferentes grupos sociais - sendo muito incisivo nas suas críticas: "a sociedade moderna, dizem muitos dos melhores sociólogos, está dominada pela ruptura desta correspondência entre actores e sistema. Por um lado, o poder concentra-se e grupos restritos controlam os fluxos de dinheiro, de influência e de informação. Aquilo a que se chama integração social pode ser reinterpretado como o controlo exercido por estes centros de poder sobre os actores sociais cada vez mais manipulados" (1992, pp. 406-407).

Um outro aspecto mostra-se de particular relevância: não poucas vezes, tem sido precisamente em nome da governança - ou se, quisermos, na abertura do Estado e das políticas públicas aos actores sociais - que se têm consolidado práticas e sistemas neocorporativos de competitividade. O carácter polissémico do conceito de governança, se lhe tem permitido uma parte não negligenciável do seu sucesso por muitas escolas de pensamento e projectos de reforma, por outro lado, deixa-o extremamente aberto a interpretações - e utilizações muito distintas (Jouve, 2003). Se apenas colocado de forma normativa e conceptual, ou utilizado de forma muito parcial num dado universo político-institucional, pode tornar-se um conceito essencialmente pós-moderno, de difícil capacidade integrante, sequer construtivista. Podendo transfigurar-se, em reflexo invertido, num veículo discursivo justificativo de panoramas políticos de menor pluralidade. A este propósito, relembremos Harvey (1996b) que efectuou uma excelente reflexão semiótica sobre os discursos na cidade, tomando em conta que os espaços de acção política podem ser tão perceptíveis ao nível material como discursivo.

Gomes (2003), juntando as pontas, é claríssimo - de tal modo, que não devemos deixar de citar toda a sua argumentação: "Existe aqui, bem entendido, o risco de se perderem de vista os objectivos estratégicos democraticamente definidos para as diversas políticas públicas e, com eles, a essência destas. A governança é uma difícil arte de marear e a corrente determinada pelas trocas sociais duma ordem que se fez negociada tem muita força. Raciocinar e agir em termos de governança permite ultrapassar as aproximações institucionais clássicas e pôr a tónica numa interacção do Estado com a sociedade civil, bem como nos problemas de coordenação que se colocam à gestão pública. Mas tal não significa que o sistema político possa ser assimilado, em nome dum empirismo supostamente realista, a um qualquer sistema de acção onde os espaços da 
gestão pública não correspondem ao domínio institucionalizado das políticas públicas, o cidadão e o utente se confundem e aos actores privados cabe o papel principal porque o Estado, supostamente recuou. Podemos dizer, em síntese, que o risco para a governança resulta, por um lado, das falhas na articulação entre o plano da representação política e o plano das negociações sectoriais e por outro lado, das tensões crescentes entre a lógica pura e dura da economia de mercado e uma lógica de radicalidade democrática" (p. 394).

Entendida e aplicada de determinada forma, a governança urbana pode assim tornar-se evocação e mesmo justificação para a construção de sistemas oligárquicos, seja através de práticas de particularismo institucional (Mozzicaffreddo, 2003) ou mesmo através da consolidação de regimes urbanos de competitividade, em lógicas de relacionamento de poules de determinados actores, estrategicamente bem direccionadas, e a que Jessop (1998) sugeriu chamar de governança heterárquica. Não surpreende, assim, que exista um número crescente de críticas às evocações simplistas da governança urbana, havendo mesmo alguns autores que chegam a sugerir que, em muitas situações, a sua utilização esconde, afinal, verdadeiros projectos de condução discricionária de sentido essencialmente neoliberal e a própria negação da afirmação colectiva na política da cidade (Jouve, id.). O que, convenhamos, é fito demasiado pesado para um conceito que, apesar dos riscos, contém propostas consideravelmente amplas de inovação e de aplicabilidade, continuando a deter um excelente potencial para a renovação da política na cidade. Para que esse potencial se manifeste de forma mais ampla, contribuindo decisivamente para a inovação da política na cidade, e para que não seja epistemologicamente absorvido por concepções heurísticas distintas, parece necessário não só a existência de uma estrutura de governo empenhada, perspicaz e bem consciente dos desafios da contemporaneidade mas, sobretudo, que tal empenhamento seja suportado por uma sociedade urbana que compreenda e que se comprometa com tais desafios. Um empenhamento que requer, seguramente, importantes doses de capital social.

\section{Capital social e estruturas motivacionais de expressão cívica}

O conceito de capital social tem sido colocado, de forma crescente, nas reflexões e conceptualizações que procuram perspectivar o aprofundamento das culturas de cooperação socioterritorial, das formas e práticas de expressão cívica mais colectivas e, no fundo, do consolidar, se necessário pela inovação, de alguns dos valores mais basilares da democracia - muito particularmente, para as escalas local e urbana. Inicialmente desenvolvido por Bourdieu $\left(1997^{3}\right)$ e ainda por Coleman (1990) foi, na materialização de uma análise empírica, melhor detalhado por Putnam (1993). Este último, no seu conhecido trabalho sobre a evolução de considerável sucesso das regiões da chamada Terceira Itália, escreveu: "o sucesso na superação dos dilemas de acção colectiva, e dos oportunismos derrotistas que levanta, depende do contexto social mais vasto em que cada situação particular é jogada. A cooperação voluntária é mais fácil numa comunidade que herdou um stock substancial de capital social, sob a forma de normas de reciprocidade e de compromisso em redes cívicas (...) capital social, aqui, refere-se a elementos de organização social, tais como confiança, normas, e redes, que melhoram a eficiência da sociedade facilitando acções coordenadas" (p. 167).

O capital social compreenderá, assim, a combinação de elementos-chave presentes na sociedade civil: confiança, expectativas, normas de reciprocidade, laços e redes de comunicação e de relacionamento. Elementos acumulados - e cumulativos - por experiências de parceria, de associativismo, de interacção e de cooperação entre diferentes actores, num quotidiano desenvolvido e maturado ao longo do tempo. Sendo um poderoso vínculo e ferramenta de accionamento de dinâmicas e de energias de toda uma comunidade, num sistema de redes de compromisso cívico e social, permite, por sua vez, a existência, a uma escala mais ampla, de melhores condições para o desenvolvimento de projectos mais articulados, mais comuns e certamente mais colectivos. Para além de um carácter necessariamente estrutural na sua

${ }^{1}$ O texto original é de 1983. 
construção - o que faz com que algumas sociedades pareçam estar historicamente mais preparadas do que outras para enfrentar determinados desafios de cada modernidade - o capital social remete igualmente para a importância dos elementos socioculturais de identidade e de pertença, não somente a um dado território, mas também a uma dada sociedade e a seus múltiplos elementos de interligação, de inter-relacionamento e de qualificação (de base cultural, económica, social, etc.). Muito especialmente quando tais elementos materializam, precisamente, expressões de cidadania e de comprometimento associativo e participativo. Sendo uma riqueza (ou um capital) de base, no essencial cognitiva e intangível, o capital social poderá, no entanto, ser razoavelmente reconhecível e mensurável através, precisamente, da análise das diferentes formas de comprometimento e de activismo.

Embora seja um debate relativamente novo nos campos da sociopolítica urbana, a relevância colocada nas capacidades cívicas e associativas de uma sociedade, para a sua qualificação (social, cultural, económica e política) vem de longe. Alexis de Tocqueville, na sua longa observação à sociedade norte-americana do início de Novecentos, sublinhou a importância de um envolvimento cívico activo e de uma concomitante existência de associações empenhadas na construção de uma consolidada democracia, reflexões que já vinham na linha de pensadores iluministas como Locke ou Montesquieu ${ }^{4}$. Mas poder-se-á ir bem mais longe - talvez mesmo aos âmagos da cidade política: há 2500 anos, Platão argumentava que os governos da cidade deviam variar de acordo com as disposições da sua cidadania - a Polis era entendida não tanto pelo seu território, mas antes pelos seus cidadãos. Desde logo, se a cidade são os cidadãos e suas formas de relacionamento, estes são então a própria política. Pouco mais tarde, Aristóteles afirmava que o homem, sendo habitante da cidade, é naturalmente um animal político - e só através da sua participação na comunidade, se torna verdadeiramente humano. É plena de simbolismo a constatação de que o nome da cidade de Atenas provém de Atenienses (os adoradores da deusa Athena) e não vice-versa (Boorstin, 1992). Apesar do declínio de Atenas (pelo pecado de, para além dos muros da sua democracia, ter querido construir um império), são as doutrinas e os ensinamentos destes filósofos e políticos (entre outros grandes como Sócrates e Péricles) que ficaram para a posteridade - e não as ideias de qualquer dos inúmeros sofistas (os da altura e todos os posteriores) vendendo retórica e suposto pragmatismo como forma de desenvolvimento.

Afirmando-se a política numa sociedade urbana - muito em termos da capacidade de expressão e de participação de cada indivíduo (como direito e como dever), o capital social afigura-se, assim, como factor primordial da sua riqueza colectiva. Uma riqueza de carácter cultural e motivacional. E que, aspecto bem relevante, por efeito de reflexividade e de interdependência, consolida a própria qualidade das instituições e das práticas políticas na cidade.

Perante as significativas transformações nos enquadramentos de acção pública e colectiva nas cidades, e particularmente face aos cenários de condução mais discricionária visando objectivos mais parcelares que colectivos, "parece assim importante introduzir a variável do capital social quando falamos do futuro das cidades e da sua capacidade para enfrentar novos desafios e processos de inovação colectiva" (Subirats, 2001, p. 4).

São, evidentemente, de diversa e poliédrica ordem os elementos que, num dado território ou cidade, proporcionam a valoração do seu capital social - o que torna inevitavelmente redutor qualquer trabalho mais racionalista de sistematização destes. No entanto, e não obstante tal inevitabilidade, parece-nos bastante curial procurar uma sistematização, não só pela perspectiva de uma melhor compreensão analítica das dimensões e variáveis basilares na consolidação de tão precioso valor, como também, e perante esse exercício e entendimento, se poder, por sua vez, perspectivar linhas de acção política e operativa, precisamente para o seu livre e sustentado fomento. Propomos a sistematização, por conseguinte, de seis dimensões pelas quais se poderão estruturar os elementos que, em correlação positiva, mostram ser basilares para a consolidação dos níveis de capital social numa

\footnotetext{
${ }^{4}$ Veja-se uma das inúmeras edições do clássico de Tocqueville, Democracy in America, nomeadamente a edição portuguesa (2001).
} 
cidade: primeiro, a própria configuração e complexidade da cidade/metrópole, quer no seu todo, quer em termos de cada um dos seus espaços e bairros; segundo, a solidez e a estrutura dos padrões de identidade e da cultura urbana dos cidadãos perante a cidade, os seus espaços e as suas redes relacionais - incluindo dimensões como as estruturas de aceitação da multiculturalidade e de sustentação de cosmopolitismo; terceiro, a existência de um universo de fluxos e de espaços de conhecimento e de discussão sobre a cidade e o que a molda; quarto, e como acima comentado, a presença activa de dinâmicas associativas e de mobilização (que, como sugerimos, não têm necessariamente os mesmos padrões, sendo esta última mais consequência dinâmica - de múltiplos elementos - do que estrutura de causalidade); quinto, a construção de uma estrutura de governança urbana direccionada para a dialéctica e para um envolvimento mais colectivo; e sexto, a existência, na sociedade urbana, de elites de carácter universalista ou, precisamente, cosmopolita.

Como é óbvio, e embora se possa reconhecer em algumas destas dimensões uma natureza mais estrutural e de contexto cultural, ao contrário de outras de natureza mais racionalista e operativa, não se colocará qualquer ordem de importância entre elas, sustentando-se como num sistema integral - cada uma terá a capacidade de condicionar e/ou potenciar todas as outras.

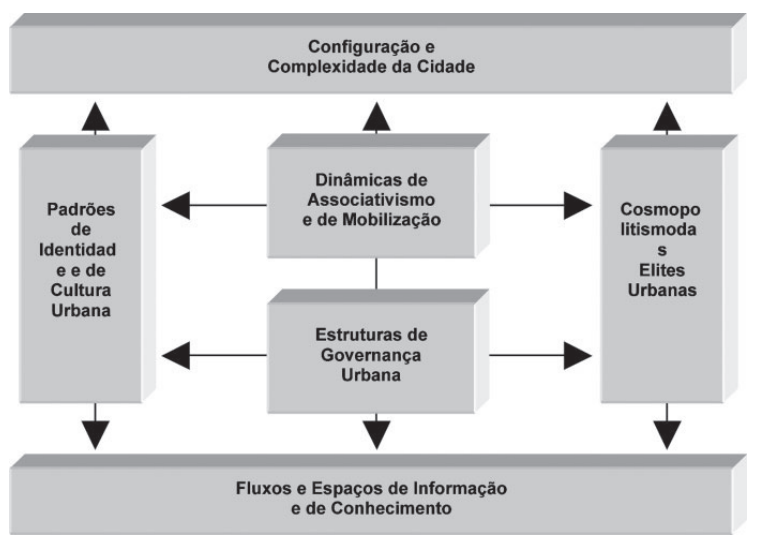

Figura 1 - Dimensões de valoração do capital social na cidade
1. A relação entre a configuração e a complexidade de uma cidade e a propensão dos seus cidadãos para uma maior ou menor cultura de expressão cívica e de responsabilização colectiva, remete-nos não só para as seculares reflexões em termos da 'cidade ideal', e da miríade de propostas urbanísticas desenvolvidas ao longo dos tempos (do fórum romano às cidades medievais, da cidade-jardim aos ensanches novecentistas, da cidade funcional lecorbusiana à cidade central reabilitada), como, evidentemente, para os mais recentes padrões de evolução metro e metapolitana. Procurando-se as potenciais associações entre os modelos de desenvolvimento desejados e, nos campos mais urbanos, os padrões morfológicos e funcionais, em primeiro lugar (estruturas e densidades das tramas, traçados, vias e parcelas, compacidades e volumetrias, etc.), mas também, evidentemente, os elementos mais cognitivos e imateriais da cidade, das suas leituras e das absorções semióticas e evidentemente estéticas da paisagem e dos sentidos, incluindo elementos como a mono ou a multifuncionalidade, a heterogeneidade e a complexidade, ou a banalização e o mimetismo. Embora os debates sobre a globalização dos padrões de relacionamento comunicacional tenham despertado múltiplas divergências, parece ser consideravelmente consensual a perspectiva de que as cidades ou os espaços urbanos ligados a uma maior complexidade (de sentires e de sentidos), a densidades estático-dinâmicas relativamente altas e a estruturas heterogéneas de diversidade, de relacionamento e de proximidade - húmus socioespacial a que Jacobs reporta a primordial importância na sustentação da própria vida urbana (1961) e a que Soja chamou de synoykismo $(2000)^{5}$ - têm uma fertilidade social que propiciará um melhor florescimento da afirmação cultural e dialéctica no espaço, e por conseguinte do capital social na cidade (Castells, 1996, Brenner, Jessop, Jones e Macleod, 2003, Borja, 2003). Em contraponto, as realidades metro e meta urbanas mais

\footnotetext{
${ }^{5}$ Para Soja, a base epistemológica do termo é plena de significado: em primeiro lugar recorda-se a obra de Charles Keith Maisels (The emergence of civilization, 1990) e a sua definição de synoecism como uma "interdependência proveniente de uma densa proximidade"; mas lembra ainda o termo clássico grego synoikismo, que define a condição de vida humana em conjunto, e que o próprio Aristóteles utiliza para descrever a essência da polis; ou ainda o mais amplo oikos, palavra raiz de termos como economia ou ecologia, e que, para Doxiades, descreve a compreensão dos assentamentos humanos, da escala da habitação à escala global.
} 
fragmentadas, mais monofuncionais, e com padrões de mobilidade e de inter-relacionamento mais fractais, ao fomentar a segmentação espacial e social, terão obviamente maiores dificuldades na sustentação de culturas mais amplas e mais colectivas de expressão. Dito de outra forma, será nos espaços (da terra e da mente) que são cidade, vista como construção social quotidiana, que verdadeiramente se poderá afirmar uma cidadania pluralista e universalista. Estará aqui, sem margem para grandes dúvidas, na escolha do tipo de espaços urbanos que construímos e que sustentamos, uma das mais vitais questões para o desenvolvimento humano e civilizacional. Muito especialmente perante o entendimento de que a sua configuração e as paisagens e dinâmicas daí resultantes, condicionam de forma significativa os sentidos e as expressões da cidadania - e como tal, em última análise, a afirmação política da sociedade.

\section{Em relação à identidade e cultura urbana} e à sua substantiva interligação com a consistência da expressão cívica numa cidade, seguimos Touraine, quando refere que "é pois do lado da cultura e não já do lado das instituições que há que procurar o fundamento da democracia" (1996, p. 160). Neste postuladoligado ao advento do novo paradigma cultural, como anteriormente escrevemos (Seixas, 2005) - os elementos de identidade colocam-se como especialmente importantes para a afirmação do capital social na cidade, no pressuposto de que um sentido de comprometimento mais colectivo é fomentado por uma consciência cultural de cariz identitário. Para Bourdieu, aliás, o capital cultural pode ser mais vital que o próprio capital social, porque afinal estrutura este (1997). Mas que tipo de identidade urbana se encontra em reestruturação - e se pode consolidar - nos espaços da cidade metapolitana e contemporânea? As reconfigurações dos seus espaços, bem como das redes sociais e de relacionamento, têm provocado grandes alterações nas dimensões de identidade local. Devido, por exemplo, ao enorme aumento das dinâmicas de mobilidade (quotidiana, residencial, laboral, individual) uma parte significativa dos indivíduos, hoje em dia, actua sobre o território tendo uma menor pelo mencos, menos reconhecível - consciência das suas interligações com um determinado território, de forma a este lhe transmitir algum tipo de responsabilidades (Martinotti, 1993). Da mesma forma, e devido às pressões decorrentes das vagas de imigração, a maioria das cidades europeias tem hoje aberta uma série de potencialidades de diversidade e de miscigenação, mas também riscos de confrontos étnico-espaciais. Neste contexto de mutação socioespacial, quando a representação territorial se torna mais difusa, as formas clássicas de interacção social tornam-se, também elas, mais difíceis de estabelecer. No entanto, para muitos (como Viegas e Dias, 2000), e apesar destas reconhecidas dificuldades, também se tem assistido a uma transformação das próprias formas de cognição e de representação social, por sua vez transformando as redes de interrelacionamento urbano e os próprios movimentos sociais (Ferreira, 2000b, Mayer, 2001).

Os espaços públicos são aqui, na valorização da consciência de cidadania, elemento particularmente relevante. Borja (1998) e Ordovás (2000), entre diversos outros, realçaram a grande importância dos 'espaços públicos de desenvolvimento cívico’ para a consolidação dos elementos identitários, e a sua interligação com uma cultura mais activa de exigência e de cidadania. Espaços de representação, contextualizadores dos valores da cidadania urbana, pelo efeito de características tais como a sua própria natureza (no mínimo, potencial) de símbolo, de centralidade, de acesso, de abertura e de multifuncionalidade, permitindo um 'sentimento de pertença' para muitos, de maior consciência dos direitos e responsabilidades de cidadania, num envolvimento do ambiente urbano e do património da cidade, entendidos assim de uma forma mais ampla - ou mais cultural (Matias Ferreira, id.). Os espaços públicos da cidade, desde que potenciados por dinâmicas de apropriação, são assim dos elementos mais vinculativos para a definição dos valores de cidadania e da própria cidade (Borja e Muxi, 2001). Daí que haja um significativo correlacionamento entre as cidades com espaços públicos de qualidade e vertebra- 
dores da própria consciência cívica, e os sentimentos de identidade e de motivação cultural para o exercício mais pleno da cidadania. Os espaços públicos, concebidos para o uso social, colectivo, multifuncional e acessível a todos, facilitam as relações sociais e são, como tal, um vital elemento de estruturação cívica, e obviamente política. Espaços vitais, expressos pelos seus benefícios 'intangíveis', que podem estar, em diversas cidades, em risco de escassa valorização, perante prioridades de valorização a curto prazo de visões mais parcelares sobre a cidade.

3. A terceira dimensão de influência do capital social numa cidade parece colocar-se, à partida, numa segunda linha de relevância em relação a outros elementos. Será porém, no nosso entender, das mais importantes, visto conter parte essencial das bases de uma consolidação cultural. Coloca a tónica na existência de um universo de conhecimento sobre a cidade e de correspondentes redes de informação e de partilha desse conhecimento. Um universo de conhecimento e de dialéctica sobre os territórios da cidade, os seus espaços e habitantes, os seus dilemas e as suas perspectivas, mostrando ser elemento igualmente determinante para o fortalecimento do capital social. Para o fomento de uma consciência cultural e identitária sobre a cidade, será particularmente relevante o velho postulado de que um maior conhecimento das coisas provoca nos indivíduos uma maior responsabilidade sobre o destino destas. Enquanto a cidade se torna mais caleidoscópica, e bem mais difícil de entender, e as suas múltiplas influências e externalidades têm um âmbito consideravelmente complexo, tal postulado obriga a ampliar as linhas de investigação e de entendimento desta, por um lado, e uma ampla divulgação de tais informações e conhecimento, por outro lado. Entendida sob a óptica da cidadania e da expressão cívica e como elemento essencial do direito à cidade, a divulgação da informação e do conhecimento sobre esta torna-se, assim, vector também basilar da própria democracia. Se as responsabilidades do Estado e dos actores públicos se compreendem de forma clara em relação à criação e manutenção de elementos qualificados de identidade tais como os espaços públicos, ou face à construção de estruturas de governança plural, também na divulgação do conhecimento tais deveres são evidentes. Por outro lado, colocam-se similares responsabilidades cívicas - se não mesmo políticas - nos actores cujas funções se baseiam na produção e na divulgação do conhecimento, designadamente as universidades, os media e os diferentes centros de investigação e think-tanks existentes numa sociedade urbana. O capital social, em importante medida, depende igualmente do dinamismo e das capacidades democráticas destes actores.

4. Tal como em muitas outras áreas, temos assistido, nas cidades e metrópoles (e como igualmente já comentámos) a transformações de considerável relevância nas dinâmicas de expressão associativa e de mobilização cívica. Desde as análises pioneiras de Marshall (1950) sobre a expressão da cidadania e os direitos dos indivíduos, às reflexões de Turner (1993), em torno das formas de expressão mais passivas ou mais activas da cidadania, a abordagem da contemporaneidade parece necessário entender as novas configurações desta. Hoje, a expressão cívica individual, em primeiro lugar, e os movimentos e as associações cívicas, em segundo, estruturam-se e agem cada vez menos como meros movimentos classicamente fordistas (sindicatos e união de trabalhadores de vária ordem, corporações profissionais, associações territoriais, associações desportivas e religiosas, etc.), mas também, e em crescente medida, como estruturas de nova organização, muitas delas inclusive menos 'territorializáveis' do que as suas congéneres clássicas, articulando-se e exprimindo-se por formas muito variadas (ambientalistas, defensores do consumidor, proprietários, inquilinos, contribuintes, condutores, pais de crianças em idade escolar, utentes de infra-estruturas, etc.). Nesta miríade de novas formas de associativismo e de expressão - incluindo, como já escrevemos, a expressão de teor individualizante, muito por via dos ambientes cibernéticos - verificamos uma considerável dificuldade de preencher os 
desfasamentos entre as clássicas formas de representação e de concertação institucional e as formas mais actuais de expressão (Saunders, 1986, Putnam, 2000). Especialmente quando, como já muitos têm notado, existe uma significativa diferença entre associativismo (que pode ser essencialmente passivo) e mobilização (reconhecidamente mais activa). Estes desfasamentos de participação das novas formas - e necessidades - de expressão da sociedade são, aliás, cerne dos mais profícuos debates políticos que se têm desenvolvido nos presentes tempos de globalização económica, de evanescimento do Estado-nação e de recentramento dos poderes regional e local. A começar, desde logo, pela escala do planeta, onde se têm procurado formas de envolvimento político mais plural perante influências político-económicas de nível global.

Não obstante uma óbvia disparidade e fragmentação, muitos movimentos e associações parecem, no entanto, deter alguma interligação entre si, ao emergirem para desafiar um dado statu quo. Na paisagem político-social da cidade, colocando em questão, por exemplo, o estado-da-arte e o statu quo de orientações no sentido da 'cidade competitiva' ou da 'cidade não solidária’ (Mayer, 2001). Embora com diversos matizes, esta é uma direcção que se acentua, na verdade, perante o crescente descrédito, em muitas cidades, em relação aos sistemas político-institucionais vigentes. $\mathrm{E}$, se algumas comunidades ou associações se colocam numa atitude meramente desconstrutivista, uma parte destas novas (bem como de algumas das velhas) expressões cívicas, parecem procurar desenvolver uma atitude de envolvimento e de parceria com diferentes actores, não só com os actores públicos mas também por via de relacionamentos horizontais com outros agrupamentos - processos de inter-relacionamento a que a presente era tecnológica e informacional dá um notável contributo (Castells, 1996). À escala da cidade, este tipo de redes de expressão e de inter-relacionamento suporta parte importante de uma cultura local de tradição weberiana. Mayer descreve estas associações e agrupamentos como “associações cívicas ou ONG enraizadas na sociedade civil (...) empenhadas na construção de capital social, ou representando elementos de capital social, numa correlação positiva com vectores de democracia política e de desenvolvimento económico" (id., p. 2). Uma correlação que, contudo, pode não ser assim tão positiva em alguns casos, como recorda ainda Mayer (2000 e 2001), em relação a contextos associativos de reivindicações essencialmente exclusivistas ou de gueto - como, por exemplo, na defesa de particularismos em espaços de condomínios fechados, ou de ideais pouco democráticos em agrupamentos de carácter discricionário. Harvey, a este propósito, tem escrito precisamente sobre os riscos de algumas ‘armadilhas comunitárias' (1992 e 1997). Daqui resulta que a construção de sistemas de governação de maior participação é um trabalho não só complexo, mas que necessita igualmente de ser balizado por valores e princípios democráticos e por importantes doses de tacto político.

5. A quinta dimensão situa-se essencialmente no campo dos princípios e dos processos da política, e remete para a construção de uma estrutura de governança urbana de natureza dialéctica, envolvente e co-responsabilizante para com os diferentes actores da cidade (e em âmbito mais geral, para com os cidadãos), procurando assim aproximá-los, por via de estruturas aprofundadas de democracia, dos processos de reflexão e de decisão na cidade. Trata-se de potenciar o empowerment dos diferentes actores de uma comunidade urbana - conceito que pode ser entendido como uma "majoração dos poderes para agir, isto é das atitudes, competências e capacidades para intervir socialmente" (Santos Silva, 2004, p. 12) - por intermédio de estruturas e de processos que permitam criar perspectivas e energias comuns ou, se quisermos, atitudes, competências e capacidades mais colectivas. Como referiu Guerra, "o empowerment político parece exigir o empowerment social" (2000b, p. 95) e o desenvolvimento de um sistema de governo mais vigoroso passa, certamente, pela capacidade deste em ampliar o próprio vigor da sociedade civil para dinâmicas de participação política e de co-responsabilização. A autora 
escreveu ainda: "Esta participação não é apenas um postulado ideológico das metodologias de pesquisa-acção, é uma exigência funcional dos próprios processos, pela simples razão de que a resolução de problemas exige o accionamento de recursos (materiais, mas também culturais e simbólicos) e estes estão geralmente na mão de um leque diversificado de actores" (id. p. 91). Uma participação em si legitimadora e que não se espera que decorra somente nos períodos eleitorais ou em formalizações estatutárias e normativas. O fomento do capital social numa cidade inclui a estruturação, no sistema de governação urbana, de espaços e de processos de discussão, de participação e evidentemente de co-responsabilização nas estratégias, nas decisões e nas acções a empreender. Nestas áreas, toma particular relevância, mais uma vez, o papel pró-activo dos órgãos públicos locais, que devem procurar consolidar e gerir - sem a querer controlar - uma estrutura de parcerias e de participação a várias escalas e domínios. Uma estrutura que, a ser desenvolvida numa base de interligação e de parceria criativa, enaltecerá afinal o próprio papel dos governos e das instituições públicas.

Diversas propostas e experiências concretas têm surgido nesta dimensão, plena de potencialidade, de renovação das democracias urbanas. Uma dimensão que, como igualmente temos discutido, não deixa de conter importantes riscos de enviesamento e de apropriação discursiva, ou mesmo epistemológica (Seixas, 2005). Daí que a construção de estruturas mais plurais de participação e de deliberação deva não só estar baseada numa forte interligação e sinergia quer com os actores institucionais e com os cidadãos, quer com as estruturas político-institucionais vigentes, mas também que detenha, em si, mecanismos de garantia dessa mesma pluralidade, dando-lhes assim uma acrescida legitimidade. Segundo Font (2001) parece óbvio, mas no entanto crucial relembrar, que uma " $b o a$ parte da legitimidade dos instrumentos participativos dependerá de que exista uma percepção generalizada de que os interesses relevantes numa determinada política pública estejam representados no processo de participação" (2001, p. 224). Podemos encontrar uma miríade de textos de descrição e de análise em torno dos diferentes processos e instrumentos de aprofundamento das parcerias e da participação cidadã actualmente em experimentação ou mesmo já em consolidação - em diversos territórios urbanos ${ }^{6}$. Alguns destes processos e iniciativas são já amplamente conhecidos, nomeadamente nos campos cívicos, tais como o envolvimento dos cidadãos em torno do orçamento participativo (surgido na cidade brasileira de Porto Alegre, e consideravelmente difundido por centenas de cidades em todo o globo), ou ainda os concelhos consultivos de cidade ou de bairro (existentes, nomeadamente, em diversas cidades francesas e espanholas). Mas os espaços e os fluxos potenciais de aprofundamento da colaboração, da participação e da governança urbana são vastíssimos: do trabalho conjunto de parceiros públicos e privados na gestão de espaços ao investimento conjunto na sua qualificação, da democracia electrónica aos grupos temáticos comunitários, dos jurados de cidadãos às deliberações em assembleias de cidadãos, da participação aberta na realização de planos estratégicos aos painéis e aos inquéritos à cidadania. Estas vias - e outras - de inovação democrática de base urbana, poderão reconsolidar elementos basilares à democracia tais como a legitimidade e a responsabilidade na acção pública e colectiva, em paralelo com a experimentação de outras questões mais instrumentais mas igualmente vitais (em redor de quem, sob que mecanismos, que fóruns e instituições desenvolver, etc.).

\section{A existência de elites urbanas de cultura} - e de carácter - cosmopolita para a consolidação de uma boa governação política é antigo objecto de análise nas ciências sociais e políticas. Para muitos, a natureza e performance dos sistemas políticos depende, em importante medida, do capital cultural e dos comportamentos das elites políticas de um dado território -

\footnotetext{
${ }^{6}$ Não obstante esta (salutar) diversidade, a referência citada - Font, 2001 - constitui um bom conjunto de reflexões analíticas em redor das múltiplas iniciativas de participação cidadã nas cidades.
} 
vistas estas, não apenas em termos dos dirigentes políticos de uma sociedade, mas incluindo também as diferentes partes superiores da hierarquia social, nos seus variados campos (Pinto e Freire, 2003). Se, por um lado, a existência (ou a inevitabilidade da existência) de elites numa sociedade condiciona as hipóteses de Estados completamente igualitários, por outro lado, são também as elites que, em não pequena medida, contribuem para a sustentação e para o funcionamento do Estado de Direito, como referem Highley e Burton, a propósito dos diferentes axiomas da teoria das elites (2003). Estes autores postulam ainda que "os esforços, compromissos e acções padronizadas das elites políticas, a nível interno, constituem as distinções mais importantes de reconhecer entre os sistemas políticos" (id., p. 278). Se bem que estas reflexões são tidas tomando como base primordial as escalas dos Estados-nação e dos seus sistemas políticos, cremos que, em considerável medida, estas perspectivas podem também ser colocadas para as elites de uma cidade (ou sociedade urbana), estendendo-se ainda a sua influência (para além da dimensão política) para as dimensões culturais da cidade. Nesta perspectiva, um carácter eminentemente cosmopolita (ou, num outro tipo de olhar, eminentemente universalista) de uma elite urbana será certamente pedra de toque ao próprio carácter das estruturas culturais e políticas da cidade. O que estrutura, por conseguinte, importantes diferenças na evolução de distintos sistemas políticos urbanos, e na evolução das próprias escolhas (e capacidades de fazer essas escolhas) de cada cidade. Primeiro, em termos de uma atenção perante as necessidades e problemáticas da cidade (o que não quer necessariamente significar entendimentos mais localistas ou regionalistas); segundo, em termos do desenvolvimento das formas de governo urbano - para formas de governo mais oligárquicas (por sistemas baseados, como vimos, em comunidades políticas, ou determinadas elites, consideravelmente fechadas e de teor discricionário) ou, inversamente, para formas de governo que procuram a pluralidade, o co-envolvimento e a construção de estruturas de acção mais colectivas, como meio de expansão das qualidades democráticas. Os trabalhos de Joana (2000) e de Borraz (1998), em torno da evolução de uma série de cidades francesas, indicavam que um dos principais elementos diferenciais mostrava ser a capacidade das diferentes elites urbanas de coordenar as instituições e os grupos sociais de cada cidade, em torno de objectivos mais colectivos. Um das grandes questões da política na cidade é, assim, a de saber se as elites urbanas se encontram esclarecidas e orientadas para as questões de cidade, e para sentidos mais amplos de governação, de formação e de conhecimento, e afinal do próprio fomento do capital social na sociedade: de fomento da identidade, de defesa dos espaços públicos de desenvolvimento cívico, de abertura e divulgação de conhecimento e de construção de estruturas de participação cívica e de governança. Ou se, por outro lado, estão estas mais concentradas na prossecução dos objectivos de comunidades políticas essencialmente fechadas e de débil inclusão política. Em termos urbanos, e para além das visões mais localistas, parece existir ainda muito para mudar. Como bem realçam Jouve e Lefévre (1999a, no caso, para sistemas de governação metropolitanos): "as cidades europeias ainda não se tornaram os vínculos de expressão e de conquista de poder de uma elite política hegemónica e autónoma das elites locais e nacionais. Mantêm-se palco de tensões entre grupos sociais, entre sistemas de representação e interesses heterogéneos produzidos há muito, e que constituem contra-poderes pujantes e eficazes, impedindo qualquer possibilidade de emergência de um modelo de governo urbano unitário. Estas são sociedades locais, sem dúvida, mas não são certamente comunidades locais, e ainda menos espaços de agregação e de mobilização que (re)nasçam sobre as cinzas de um Estado que encarna uma ordem política ultrapassada" (p. 44). Para Crozier (1995), a razão essencial da crise das elites europeias (não somente locais, mas certamente muito urbanas) encontra-se na sua presente incapacidade de renovação intelectual, presa que está nos jogos de reciprocidades de interesses, no âmbito de sistemas crescentemente desfasados das realidades. Há, assim, que investir absolutamente na inteligência e na criatividade urbanas, numa perspectiva 
de absorção - ou melhor, de contaminação pelos sistemas político-administrativos e de governação, das correntes de inovação que podem ocorrer nas áreas mais culturais e intelectuais da sociedade urbana.

Como elemento vital da afirmação de uma cidade, da sua própria consistência e morfologias várias que a compõem - e no entendimento da cidade como construção social e política - o capital social detém uma estrutura cuja essência será, antes de tudo, cultural - sendo, em considerável medida, estruturado pelo que Bourdieu designou como capital cultural (1997). Mesmo que alguma das dimensões de valoração aqui sistematizadas possa não sugerir tão directa interligação (como, por exemplo, a configuração da cidade), como elementos basilares da urbanidade todas elas serão, na verdade, resultantes de redes de construção eminentemente culturais. Assim, particularmente para o caso da cidade, e perante o actual contexto de mudança de paradigma, terá talvez maior solidez e maior propriedade o conceito de capital sociocultural. Apesar da ordem relativamente comum dos desafios e das pressões com que hoje as diferentes cidades ocidentais têm que se confrontar, será através das diferenças nas características e nas energias próprias ao capital sociocultural de cada uma que se consubstanciarão as razões e as essências dos diferentes caminhos por elas tomados. A solidez desenvolvida nas últimas décadas do (ou de partes do) capital sociocultural da cidade de Barcelona (pelo menos até meados dos anos 1990) permitiu-lhe a configuração, certamente, de uma estrutura evolutiva - e um protagonismo dessa mesma evolução - consideravelmente distinta da sucedida na cidade de Lisboa apesar de, nesta, o seu capital sociocultural se ter igualmente qualificado (embora de todo com similar consistência e capacidade de protagonismo colectivo).

É, obviamente, de carácter axiomático a interligação entre o capital sociocultural de uma cidade e a sua potencial estruturação sociopolítica de governança urbana. Tendo-se colocado a governança como uma das dimensões (entre seis) de valoração do capital social e cultural da cidade, este exercício conceptual de todo pretende subvalorizar este conceito, antes o pretendendo interligar directamente (por linhas de desenvolvimento essencialmente políticas e racionalistas) ao próprio fortalecimento da cidadania e do seu exercício. Objectivo natural será o fomento de estruturas e de fluxos de governança numa sociedade urbana que, também assim, desenvolva um capital sociocultural forte e dinâmico, efervescente de iniciativas e de energias, nos seus diferentes elementos de valoração. Uma cidadania activa e atenta, que se estenda para além das clássicas associações e comunidades mais corporativas, é a via mais consolidada para que os espaços de governação da cidade não fiquem excessivamente ocupados por estratégias discricionárias e particulares. Confrontando e avaliando, de forma mais activa, as instituições de governo e a administração pública com a sua necessidade de um estratégico, eficiente e equitativo serviço público. Participando, sob diversas formas e escalas, na construção das dinâmicas de governabilidade da cidade. E obrigando, assim, ao desenvolvimento de um Estado mais exigente consigo mesmo, mais exigente do que um Estado meramente bom investidor ou mesmo bom regulador. Os líderes políticos e as elites urbanas, por sua vez e, mais racionalmente, os próprios agentes de mercado, que na maioria das situações são os primeiros a reagir - poderão ter uma crescente preocupação na compreensão, assimilação e, provavelmente, no fomento de novas formas de envolvimento, de integração e de co-responsabilização. Uma evolução que, numa leitura simplista, poderá ser vista como contrária aos poderes clássicos de representação mas que, se crescentemente reconhecida, poderá tornar-se num potencial social, político e ainda económico. 


\section{Referências bibliográficas}

AMIN, Ash, e Hausner, Jerzy (1997) "Interactive Government and Social Complexity", in Amin, Ash e Hausner, Jerzy (ed) Beyond Market and Hierarchy, Edward Elgar, Cheltenham.

BAGNASCO, Arnaldo e Le Galès, Patrick (ed.) (2000) Cities in contemporary Europe, Cambridge University Press, Cambridge.

BENKO, Georges, e Lipietz, Alain (1994) As regiões Ganhadoras - Distritos e Redes, os novos paradigmas da geografia económica, Celta Editora, Oeiras.

BENNETT, Richard (1997) "Administrative Systems and Economic Spaces", in Regional Studies, 31: 323-336.

BOORSTIN, Daniel (1992) The Creators - A History of Heroes of the Imagination, Random House, New York.

BORJA, Jordi (2003) La ciudad conquistada, Alianza Editorial, Madrid.

BORJA, Jordi, (1998) "Ciudadanía y espacio público", in Subirós, P. (ed.) Ciutat real, ciutat ideal - Significat i funció a l'espai urbà modern, Urbanitats n. ${ }^{\circ}$ 7. Centro de Cultura Contemporània de Barcelona.

BORJA, Jordi, e Muxi, Zaida (2001) L'espai Públic: Ciutat i Ciutadania, Diputació de Barcelona.

BORRAZ, Olivier (1998) «Pour une sociologie des dynamiques de l'action publique locale», in Balme, R., Faure, A., e Mabileau, A. (dir.) Politiques locales et transformation de l'action publique en Europe, CERAT, Grenoble.

BOURDIEU, Pierre (1997) “The forms of capital”, in Halsey, A., Lauder, H, Brown, P. e Wells, A. Education: culture, economy, society, Oxford University Press, Oxford.

BRENNER, Neil, Jessop, Bob, Jones, Martin e Macleod, Gordon (ed.) (2003) State/Space in Question, Blackwell Publishing, Oxford.

CASTELLS, Manuel (1996-1998) The information age: Economy, Society and Culture, Blackwell Publishers, Oxford.

CET (Centro de Estudos Territoriais) (2005) Políticas públicas de revitalização urbana, Relatório efectuado no âmbito da preparação do QREN (Quadro de Referência Estratégica Nacional), para o Observatório do QCA/DGDR, Lisboa.

COHEN, Michael (2000) Fundamentalism, Perception and Diversity: Looking through an Urban Kaleidoscope, Paper presented in the opening session of the master Gestion de Ciudades, UPC, Barcelona.

COLEMAN, James (1990) Foundations of Social Theory, Belknap, Cambridge, MA.

CROZIER, Michel (1995) La crise de l'intelligence. Essai sur l'impuissance des élites à se reformer, InterEditions, Paris.

CROZIER, Michel, e Friedberg, Eberhard (1977) L'acteur et le système: les contraintes de l'action collective, Seuil, Paris.

DE TOCQUeVILle, Alexis (2003) Da Democracia na América, Principia, Cascais.

DUNLEAVY, Patrick (1980) Urban Political Analysis, Macmillan Press, Londres.
ESSER, Josef, e Hirsch, Joachim (1994) "The crisis of Fordism and the dimensions of a 'Post-Fordist' Regional and Urban structure" in Amin, A. Post-Fordism: A reader, Blackwell, Oxford.

FERNANDES, António Teixeira (2004) "Democracia, descentralização e cidadania", in Viegas, José Manuel, Pinto, António Costa e Faria, Sérgio, Democracia - Novos desafios e novos horizontes, Celta Editora, Oeiras.

FERREIRA, Vítor Matias et al. (2000b) Condição Social, Ambiente Urbano e Qualidade de Vida - Observação Prospectiva da Metrópole de Lisboa, projecto de investigação integrado no Observatório do Ambiente Urbano OBSERVA/ISCTE, Lisboa.

FONT, Antonio (2001) "Planejament urbanistic per al segle XXI. L'experiencia recent de Cataluny», in Urban, n. ${ }^{\circ} 5$, Madrid.

GAUDIN, Jean-Pierre e Novarina, Gilles (1997) Politiques Publiques et négociation: multipolarités, flexibilités, hiérarchies, CNRS Éditions, Paris.

GOMES, Salis (2003) “A avaliação das políticas públicas e a governabilidade" in Mozzicafreddo, Juan Gomes, Salis e Batista, João (org.) (2003) Ética e administração - como modernizar os serviços públicos, Celta Editora, Oeiras.

GUERRA, Isabel (2006a) Participação e acção colectiva. Interesses, conflitos e consensos, Principia, Cascais.

GUERRA, Isabel (2002) "Cidadania, exclusões e solidariedades. Paradoxos e sentidos das "novas políticas sociais" in Revista Crítica de Ciências Sociais, 63, Lisboa.

GUERRA, Isabel (2000b) Fundamentos e processos de uma sociologia de acção - O planeamento em ciências sociais, Principia, Cascais.

HARVEY, David (1997) "The new urbanism and the communitarian trap" in Harvard Design Magazine, Winter/Spring, 68-69.

HARVEY, David (1996b) Justice, nature and the geography of difference, Blackwell Publishers, Oxford.

HARVEY, David (1992) Urbanismo y desigualdad social, Siglo XXI, Madrid.

HIGHLEY, John e Burton, Michael (2003) "Elites, Classes políticas e democracia no século XXI" in Pinto, António Costa e Freire, André Elites, Sociedade e Mudança Política, Celta Editora, Oeiras.

HIRST, Paul (1993) Associative Democracy, Polity Press, Cambridge.

JACOBS, Jane (1961) Morte e vida de grandes cidades, Martins Fontes, São Paulo (edição de 2000).

JESSOP, Bob (1998) "The rise of governance and the risks of failure: The case of economic development", International Social Science Journal 155, 29-45.

JESSOP, Bob (1994) Post-Fordism and the State in Amin, Ash Post-Fordism: A reader, Blackwell, Oxford. 
JOANA, Jean (Coord.) (2000) «Qui gouverne les villes?», Pôle Sud - Revue de Science Politique de l'Europe Méridionale, n. ${ }^{\circ} 13$.

JOUVE, Bernard (2003) La gouvernance urbaine en questions, Elsevier, Paris.

JOUVE, Bernard e Lefèvre, Christian (ed.) (1999a) Villes, métropoles: les nouveaux territoires du politique, Anthropos, Paris.

JUDGE, David (1995) "Pluralism" in Judge, David et al., Theories of urban politics, Sage Publications, Londres.

LE GALÈS, Patrick (2000) «Private-sector interests and urban governance», in Bagnasco, Arnaldo, e Le Galès, Patrick (ed.) (2000) Cities in contemporary Europe, Cambridge University Press, Cambridge.

LE GALÈS, Patrick (1995) Du Gouvernement des villes à la Gouvernance urbaine in Revue Française de Science Politique 45 (1): 57-95.

LINDBLOM, Charles (1977) Politics and Markets: The world's political economic systems, Basic Books, Nova Iorque.

LIPIETZ, Alain (1994) "Post-Fordism and democracy" in Amin, Ash Post-Fordism: A reader, Blackwell, Oxford, 338$-358$

LORRAIN, Dominique (2000a) "The construction of urban services models", in Bagnasco, Arnaldo, e Le Galès, Patrick (ed.) (2000) Cities in contemporary Europe, Cambridge University Press, Cambridge.

MALONEY, William, Smith, Graham e Stoger, Gerry (2000) "Social capital and urban governance: adding a more contextualized top-down perspective", in Political Studies, $48,823-884$

MARSHALL, Thomas (1950) Citizenship and Social Class and Other Essays, Cambridge University Press, Cambridge.

MARTINOTTI, Guido (1993) Metropoli: La nuova morfologia sociale della città, Il Mulino, Bologna.

MAYER, Margit (2001) Transformations in urban struggles: from social movement to social capital?, Documento apresentado na conferência The City, Social Justice and Redistributive Justice, Amsterdam.

MAYER, Margit (2000) "Social movements in European Cities: transitions from the 1970s to the 1990s" in Bagnasco, Arnaldo, e Le Galès, Patrick (ed.) Cities in contemporary Europe, Cambridge University Press, Cambridge.

MAYER, Margit (1994) "Post-Fordism in city politics" in Amin, Ash Post-Fordism: A reader, Blackwell, Oxford.
MOZZICAFREDDO, Juan (2003) "A responsabilidade e a cidadania na administração pública", in Mozzicafreddo, Juan, Gomes, Salis, e Batista, João (org.) Ética e administração como modernizar os serviços públicos, Celta Editora, Oeiras.

NEL.LO, Oriol (2001) Ciutat de ciutats, Editorial Empúries, Barcelona.

ORDOVÁS, María José (2000) Políticas y estrategias urbanas - La distribución del espacio privado y público en la ciudad, Editorial Fundamentos, Madrid.

PINTO, António Costa, e Freire, André (2003) Elites, Sociedade e Mudança Política, Celta Editora, Oeiras.

PUTNAM, Robert (2000) Bowling alone - The collapse and revival of American community, Simon \& Schuster Paperbacks, Nova Iorque.

PUTNAM, Robert (1993) Making Democracy work: civic traditions in modern Italy, Princeton University Press, Princeton.

SANTOS SILVA, Augusto (2004) "Sociedade civil, democracia local e desenvolvimento", in Viegas, José Manuel, Pinto, António Costa e Faria, Sérgio Democracia - Novos desafios e novos horizontes, Celta Editora, Oeiras.

SAUNDERS, Peter (1986) Social Theory and the Urban Question, Hutchinson, Londres.

SHORT, John (1989) The Humane City, Blackwell Publishers, Oxford.

SEIXAS, João (2005) "A cidade na encruzilhada: novas realidades e novos desafios para a cidade europeia contemporânea", in Cidades, Comunidades e Territórios, n. ${ }^{\circ}$ 11: 105-122, CET/ISCTE, Lisboa.

SOJA, Edward (2000) Postmetropolis - critical studies of cities and regions, Blackwell Publishers, Oxford.

SUBIRATS, Joan (2001) Ciudad: Proyecto, Gobierno y responsabilidades colectivas, Documento apresentado no Seminari Model Barcelona, Centro de Cultura contemporània de Barcelona, Outubro.

TOURAINE, Alain (1996) O que é a democracia, Instituto Piaget, Lisboa.

TOURAINE, Alain (1992) Critique de la Modernité, Librairie Arthéme Fayard, Paris.

TURNER, Bryan (ed.) (1993) Citizenship and Social Theory, Sage Publications, Londres.

VIEGAS, José Manuel, e Dias, Eduardo (ed.) (2000) Cidadania, Integração e Globalização, Celta Editora, Oeiras. 